\title{
Perspectives on use of personal alarms by older fallers
}

This article was published in the following Dove Press journal:

International Journal of General Medicine

10 August 2010

Number of times this article has been viewed

Kylie Johnston'

Karen Grimmer-Somers'

Michele Sutherland ${ }^{2}$

'International Centre for Allied

Health Evidence, University of South

Australia, Adelaide; ${ }^{2}$ Falls Prevention

Unit, Department of Health,

Government of South Australia,

Adelaide, Australia
Correspondence: Kylie Johnston International Centre for Allied Health Evidence, Division of Health Sciences, University of South Australia, C7-64, Centenary Building, City East Campus, North Terrace, Adelaide, SA 500I, Australia

Tel +6I8 83022086

Fax +6I8 83022766

Email kylie.johnston@unisa.edu.au
Background: Personal alarms are proposed as a reliable mechanism for older people to obtain assistance after falling. However, little is known about how older people feel about owning and using personal alarms.

Aim: This paper reports on experiences of independently living older people, who have recently fallen, regarding alarm use and their independence.

Method: Volunteers older than 65 years who had sustained a fall in the previous six months were sought via community invitations. Semistructured telephone interviews were conducted to gain information about their fall and their perspectives on personal alarm use. Interviews were content-analyzed to identify key concepts and themes.

Results: Thirty-one interviews were conducted. Twenty callers owned personal alarms. Four subgroups of older fallers were identified; the first group used personal alarms effectively and were advocates for their benefits, the second group owned an alarm but did not use it effectively, the third group did not own alarms mostly because of cost, although were receptive to an alarm should one be provided, and the fourth group did not have an alarm and would not use it even if it was provided.

Discussion: Personal alarms produce positive experiences when used effectively by the right people. The cost of personal alarms prohibits some older fallers from being effective alarm users. However, other elderly fallers remain unwilling to consider alarm use even if one was provided. In view of their cost, personal alarms should be targeted to people who will benefit most. Alternative strategies should be considered when alarms are unlikely to be used appropriately.

Keywords: personal alarm devices, falls, older people, patient perspective

\section{Background}

The challenge for health services of providing appropriate support for an aging population has been recognized worldwide. As in other countries, Australian government strategies have been implemented in the last decade to encourage older people to remain living safely in their own homes for as long as possible. ${ }^{1}$ Community and inhome support programs have aimed to assist older people who can no longer undertake daily activities safely or efficiently. ${ }^{2}$ These strategies have resulted in increasing numbers of older people living independently. ${ }^{3}$

Falls are a common cause of morbidity in older people living independently at home. Outcomes are more severe if the faller is unable to get up from the floor. ${ }^{4}$ Older fallers often require assistance from the ambulance service for, at best, a "lift" to upright and a general check over, and at worst, transport to hospital for injury management. Unless help arrives quickly, an undesirable outcome of a fall is a lengthy period of 
time spent on the floor, a "long lie". Lying on the floor after a fall for an extended period of time (eg, an hour) has been associated with serious injury, hospital admission, and change of living arrangements to long-term care. ${ }^{5}$ Personal experience of a long lie, or knowing about others who have experienced such an event, is believed to contribute to older people's fear of falling. Fear of falling leads to a cycle of self-restriction of activity and a resultant decrease in physical function. ${ }^{4,6}$ Concerned family or carers may also restrict older persons' activities, with similar long-term outcomes on independent function.

The incidence of long lies is largely unknown. Gathering this information relies on self-reporting after a fall, when people may be in pain or have reduced levels of consciousness. In a study of community-dwelling people over 90 years of age, $30 \%(n=20)$ of those who fell reported that they were on the floor for an hour or more, and for a further $9 \%(n=6)$ the maximum time on the floor was unknown. ${ }^{5}$ Another study reported that $47 \%$ of non-injured community-dwelling fallers aged over 70 years ${ }^{7}$ were unable to get up from the floor without assistance. Risk factors independently associated with inability to get up included an age of at least 80 years, depression, poor balance, and gait.

One support strategy for people who are at risk of falling is a personal alarm or a personal response system. This is proposed as a reliable means for older people, particularly if they live alone, to obtain help quickly in an emergency. ${ }^{8,9}$ A recent study in Western Australia found that older people receiving community services who had a personal alarm wore it most of the time, and $32 \%$ had activated their alarm in an emergency, which was a fall on $56 \%$ of occasions. The largest reported impact on users' lives was gaining faster assistance in an emergency, followed by reducing anxiety about falling and increasing the time users could remain safely living at home. ${ }^{10}$ However, sometimes personal alarms are not used when the individual fails to recognize the need for emergency action, or is concerned about the consequences of seeking help. ${ }^{11}$ This research investigated the experiences and perceptions of independently living older people who had recently fallen, and examined differences between those who did and did not use a personal alarm.

\section{Methods}

\section{Sample}

Volunteers aged 65 years and over who had sustained a fall in the previous six months and were willing to tell of their experiences.

\section{Study design}

Qualitative study seeking information on the fall, whether older fallers had used a personal alarm or other means to gain help (eg, calling the ambulance, assistance of family members or neighbors), and their perspectives on the use (or not) of an alarm.

\section{Subject recruitment}

A one-page flyer advertising the study and promoting the caller line was disseminated to Metropolitan and Country South Australian Department of Health staff, and selected metropolitan general practice and physiotherapy facilities.

\section{Data collection}

Semistructured telephone interviews were conducted via a dedicated caller line in May 2009. When the caller line was unattended, an answering machine message asked volunteers to leave their contact details, and callers were telephoned by the researcher the next business day. All country callers were telephoned by the researcher in order to minimize the cost of a lengthy long-distance call. After explanation of the study to the caller, verbal consent was gained to proceed, including audiotaping of the interview. Interviews took up to 20 minutes. The semistructured interview guide is outlined in the Figure 1. Interview questions were chosen to gain data on the experience of the fall (what happened, how help was obtained, harm sustained), alarm use or nonuse and reasons why, and perceptions on alarm use or nonuse (value of an alarm, and benefits and barriers to alarm use). Ethics approval was provided by the relevant Human Research and Ethics Committees of the authors' institutions.

\section{Data analysis}

Interviews were transcribed, and later replayed for validation by the original interviewer. Transcript content was analyzed to identify key concepts and themes. Themes were compared for participants who did and did not use a personal alarm, and clusters of themes were generated. Analysis took place concurrently with ongoing interviews.

\section{Theme conversion}

Congruencies and dissonances between themes was identified in order to identify groups of fallers with different perspectives, and whose use (or not) of a personal alarm reflected their perspectives, experiences, and attitudes to personal safety. Representative quotations were identified to describe different groups of alarm users. 


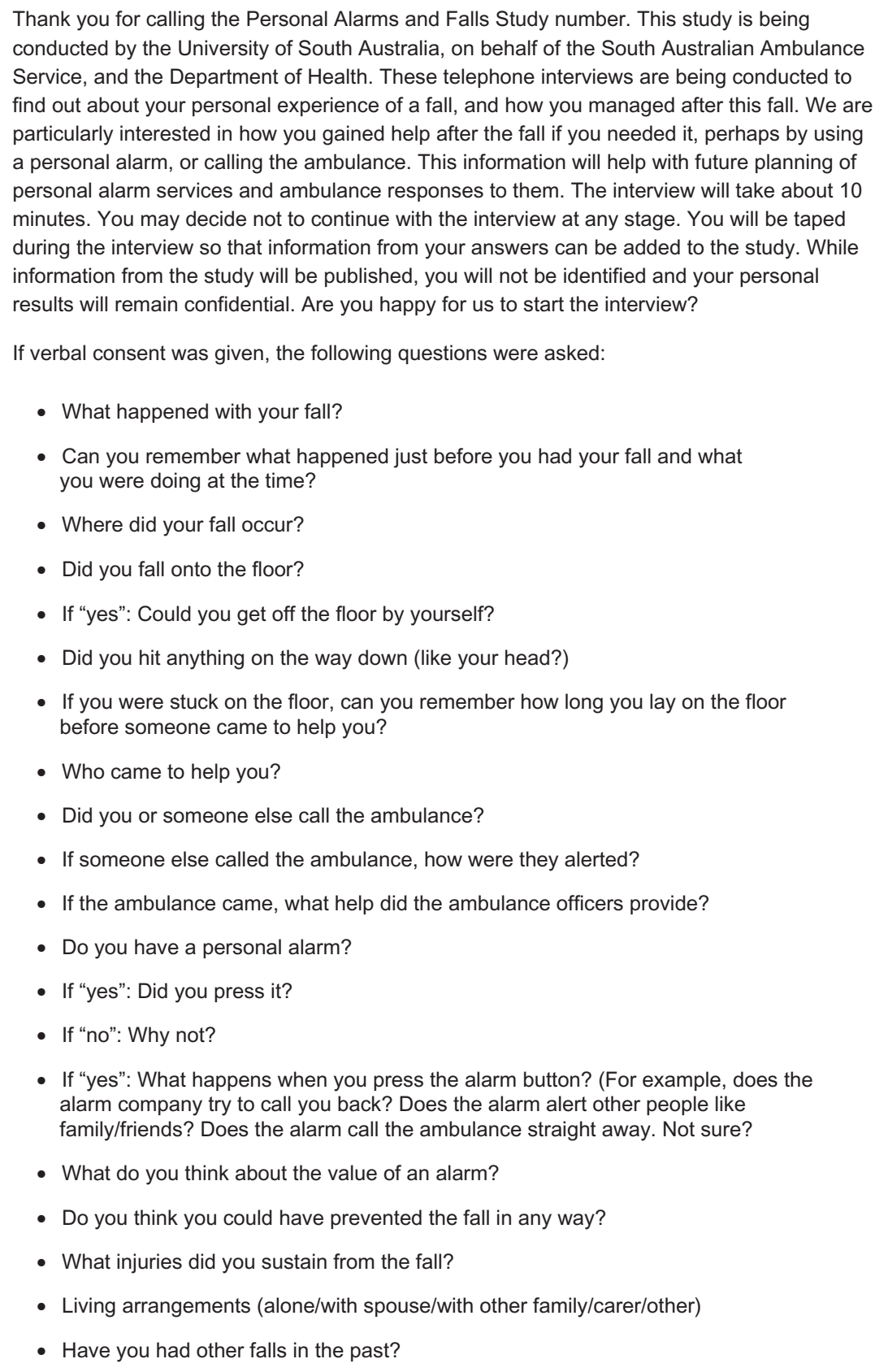

- If "yes": What happens when you press the alarm button? (For example, does the alarm company try to call you back? Does the alarm alert other people like family/friends? Does the alarm call the ambulance straight away. Not sure?

- What do you think about the value of an alarm?

- Do you think you could have prevented the fall in any way?

- What injuries did you sustain from the fall?

- Living arrangements (alone/with spouse/with other family/carer/other)

- Have you had other falls in the past?

Figure I Semistructured interview guide.

\section{Results and discussion}

Thirty-one volunteers responded, and all were interviewed. Interviews ranged from five to 20 minutes in length. Twenty-six respondents were women (84\%). Sixteen interviews were conducted with people living in regional South Australia (52\%), with the remainder from metropolitan Adelaide. All respondents had experienced a recent fall, and $64.5 \%$ of respondents owned personal alarm devices. Data saturation occurred after the twentieth interview, when it became apparent that no new themes were emerging.
Four groups of fallers were identified from the interview themes:

- Had an alarm and a positive perception of alarm use (effective users)

- Had an alarm and a negative perception of alarm use (ineffective users)

- Did not have an alarm but had a positive perception of alarm use (potential effective alarm users)

- Did not have an alarm and had a negative perception of alarm use (nonalarm users) 
Each group had different perspectives about alarms, including motivators for ownership and willingness to use alarms. The key themes from the interviews are summarized in the Table 1.

\section{Contextualizing the findings}

Thematic analysis of the interview data identified "using a personal alarm to call for help after a fall" as a "target" behavior, with study participants at different stages of uptake. The experiences of alarm users were put into context using the transtheoretical model of behavior change. ${ }^{12}$ This model describes six stages of readiness for change, with respect to a specific behavior (precontemplation, contemplation, preparation, action, maintenance, and termination). Examination of the interview data demonstrated that participants' behavior and perceptions with regard to personal alarm use aligned with the key features of stages described in this model.

\section{Effective alarm users}

Effective alarm use was associated with positive outcomes after a fall, positive faller perceptions about these outcomes, and more adaptive strategies for fall prevention compared with the other subgroups. Many of the fallers in this group described their lives as being of high quality. Perceived benefits of personal alarms included personal safety and reassurance, peace of mind for families, and provision of a potentially life-saving backup system. Their alarm uptake was often motivated by a number of bad personal experiences (eg, previous injury or long lie after a fall).

Using the transtheoretical model of behavior change, ${ }^{12}$ these fallers appeared to be at the action or maintenance stage, and were "alarm champions" and evangelical about alarm use. These fallers could have the positive potential to influence persons who are unaware of, or just beginning to consider the benefits of, using a personal alarm.
"It costs me \$200 a year for a full service but that is really nothing when you think about it, as to what harm could be done so I am quite happy to pay for it. It's about $\$ 4$ a week I pay so that is cheap for peace of mind ... even when I was out in the garden I could easily push the button and they'd be there. So when anyone says 'I don't wear mine' I get cranky. Well they still have to pay for it and I know another lady who doesn't wear hers and she has had many falls and people coming in to do her medication every morning, and once a week or at least once a week they find her on the floor where she's been all night and she still wouldn't wear her alarm. To me that's ridiculous".

\section{Ineffective alarm users}

Although this group of fallers also owned a personal alarm, it was rarely worn, its performance was not understood, and/or the alarm type appeared unsuitable for their needs. Several of this group who had fallen outside their home did not realize the pendant (around their neck) could still raise the alarm, provided the faller was within range of the receiver attached to their telephone service. People who did not wear their alarms described them as obtrusive, uncomfortable, or unnecessary. These responses often appeared to be associated with expressions of fatalism, resignation, or denial of fall risk.

These individuals were potentially at variance with their perceived and actual position in the stages of change. Despite the fact that they were in possession of a personal alarm, their attitude to it was at the precontemplation or contemplation stage.

\footnotetext{
"The alarm lives in my bedroom. You really need a small one on your wrist or something. It dangles .... If I go out to do something in the garden I don't want it flapping around in front of me. Too big to sort of hang off my wrist. I'm not sure whether I did the right thing getting it or not you know? .... I
}

Table I Key themes identified in faller interviews

\begin{tabular}{|c|c|c|c|c|c|c|c|}
\hline & \multirow{2}{*}{$\begin{array}{l}\text { Faller } \\
\text { experience } \\
\text { regarding alarm }\end{array}$} & \multirow{2}{*}{$\begin{array}{l}\text { Faller } \\
\text { outcomes }\end{array}$} & \multirow{2}{*}{$\begin{array}{l}\text { Faller } \\
\text { response to } \\
\text { outcomes }\end{array}$} & \multicolumn{2}{|c|}{ Faller perceptions of alarm } & \multirow{2}{*}{$\begin{array}{l}\text { Other } \\
\text { strategies used }\end{array}$} & \multirow{2}{*}{$\begin{array}{l}\text { Alarm uptake } \\
\text { facilitators/ } \\
\text { detractors }\end{array}$} \\
\hline & & & & Benefits & Barriers & & \\
\hline \multirow[t]{2}{*}{$\begin{array}{l}\text { Falls with } \\
\text { alarm }\end{array}$} & Positive & $\begin{array}{l}\text { Quick medical } \\
\text { attention }\end{array}$ & Feel safe & $\begin{array}{l}\text { Benefits } \\
\text { outweigh } \\
\text { cost }\end{array}$ & $\begin{array}{l}\text { Only works at } \\
\text { home, but do } \\
\text { not go out alone }\end{array}$ & $\begin{array}{l}\text { Combined } \\
\text { modalities }\end{array}$ & $\begin{array}{l}\text { Advised by GPI } \\
\text { family }\end{array}$ \\
\hline & Negative & Did not wear it & $\begin{array}{l}\text { Possible } \\
\text { intention } \\
\text { to change }\end{array}$ & $\begin{array}{l}\text { Minimal, as } \\
\text { does not } \\
\text { use it }\end{array}$ & $\begin{array}{l}\text { Obtrusive } \\
\text { Confusion about } \\
\text { how it works }\end{array}$ & & $\begin{array}{l}\text { Responded to } \\
\text { advertising }\end{array}$ \\
\hline \multirow[t]{2}{*}{$\begin{array}{l}\text { Falls with } \\
\text { no alarm }\end{array}$} & Positive & Neighbors helped & $\begin{array}{l}\text { Burden on } \\
\text { others }\end{array}$ & $\begin{array}{l}\text { Personal peace } \\
\text { of mind }\end{array}$ & Cost & $\begin{array}{l}\text { Phone check- } \\
\text { in systems }\end{array}$ & \\
\hline & Negative & $\begin{array}{l}\text { Serious injury } \\
\text { Long lie }\end{array}$ & $\begin{array}{l}\text { Pressure to } \\
\text { get alarm }\end{array}$ & $\begin{array}{l}\text { Family peace } \\
\text { of mind }\end{array}$ & $\begin{array}{l}\text { Threat to self } \\
\text { perception }\end{array}$ & $\begin{array}{l}\text { Be more } \\
\text { careful }\end{array}$ & Do not need it \\
\hline
\end{tabular}


had it over a year ago I think, I've never used it as an alarm because I've never got it with me when I need it".

\section{Potential effective alarm users}

Cost was the key factor in the decisional balance about whether or not to get an alarm for a significant subgroup of respondents. This group consisted of people who had experienced one or more falls, often associated with a wait of more than one hour on the ground for help, and had obtained opportunistic help from others. They felt an alarm was a good idea, but they could not afford it. This group used a mix of strategies to manage in the absence of an alarm, including restricting activities in order to be more careful, "checking in" using home and mobile phones with their partner, friends, or neighbors, or simply being reliant on partners always to be available. However, this last strategy was often counteracted by negative feelings of being burdensome to another person.

This group included people with a history of falls or who described a coexisting medical condition that put them at high risk from falls. Their positivity about the benefits of an alarm for them suggested that subsidizing the cost of an alarm was likely to lead to effective use. This group was potentially at the contemplation stage, and with funding, could move to the action stage of behavior change.

"A personal alarm is marvelous but not many people can afford it. (My fall) has made me a bit wary. I will be very, very careful in the future all the time. I have got neighbors that I can call on but that's not fair is it? ... I would like to have an alarm ...."

\section{Nonalarm users}

Interviews with the fallers who did not own and did not wish to own alarms highlighted more negative outcomes and perceptions than fallers in any other subgroup. Nonalarm use was associated with negative faller outcomes such as a previous long lie, serious injury, loss of confidence, or fallers describing things as "very hard" or feeling "very nervous now". Interviewees in this subgroup expressed a "tug of war" between a previously held belief of their independence and health, and facing a new reality of being at risk of serious injury from a fall. Interviewees expressed frustrations with family pressure to get an alarm which they believed posed threats to their identity, trying to manage alone although finding things getting harder and harder, and trying to stay active whilst being more careful to avoid falls.

"My neighbor didn't hear me. I did call out after a while - you feel a bit stupid on the floor you know .... eventually dusk came .... so I thought it is no use, I will try and make myself as comfy as possible as I couldn't lift myself up to get to the four telephones. I did manage to get myself a heavy cushion from the back of the settee .... And I thought if I sit up against that I will be comfortable .... which of course I wasn't, but even so, and so things happened .... And my son wants me to get one of these alarms. I do have my neighbors .... they help you know. Sometimes I will take the stick with me up to the bedroom for example .... So this is how I am managing at the moment and I'm going to get rid of the toilet thing and have a rail put on the wall. Yes it would be easier to get rid of that. Then I have found someone who can do the extra hour for me cleaning. So that's ok. I suppose I should get one of these alarms but I don't fancy one. None of us do".

Strategies to address prevention of falls and harm from falls in this subgroup would need to take into account the faller's stage of readiness for change (precontemplation or contemplation) and their beliefs. For example, amelioration of alarm cost would be insufficient to promote effective alarm use for this subgroup.

\section{Promotion of alarm use}

Identification of the four groups of alarm users indicated that, in this sample, personal alarms should not be distributed indiscriminately based on broad categorizations such as age or living-alone arrangements. It is likely that wastage would occur if the alarm user was not screened and the alarm system not individualized. It also highlighted the importance of alarm providers regularly determining existing clients' understanding of their services, and reinforcing information on effective use of alarms. Factors promoting, and detracting from, alarm uptake differed between the subgroups of fallers, and thus the "fit" of alarms to individuals appears critical to ensure that the right people use the right alarm system.

\section{Unsuitable alarm users}

Of the alarm owners in this sample, it appeared that alarms were not suitable when the alarm owner was confused and living at home alone, or had declining function and was struggling to remain independent. Although confused people were not targeted in this study, one volunteer in the study was unable to describe how the alarm worked and could not identify whether she had used an alarm in the past. She reported that the alarm's main benefit was for her family, who felt she would now be able to get help if needed. However, due to this caller's confusion, it appeared unlikely that the alarm would be used effectively in an emergency, and may 
have created a false sense of security for the family regarding the user's well being. Another interview found that a very frail elderly participant did not press her alarm because she did not want to be taken to hospital, despite having fallen and sustained a fracture. Admission to hospital was associated with fear of being unable to return home. She was unwilling to use her alarm because she felt it would precipitate loss of independence.

\section{Catalysts for alarm uptake}

For some interviewees, the experience of having a fall with a long lie was the catalyst for acquiring an alarm. This experience was described as a "wake-up call" or "I learned my lesson". Subsequently, a positive experience of obtaining quick access to medical attention using the alarm often reinforced the decision to obtain an alarm.

Family or health professionals facilitated alarm uptake in the subgroup of effective alarm users. General practitioners and domiciliary care staff were often cited as influential in facilitating an older person to obtain an alarm. However, in the other subgroups (alarm nonusers, ineffective alarm users), family suggestions about alarms were perceived negatively.

\section{Alternatives to personal alarms}

Potential alarm users (for whom alarm cost was prohibitive) described check-in systems with partners, family, carers, or organizations (including Red Cross TeleCross) using home and mobile telephone networks. One caller suggested mobile telephone companies could promote a simple handset and fee schedule, with a number of preprogrammed numbers, aimed at this group of people who need to use the telephone for personal safety reasons. Situations where a phone system did not work as planned in the event of an emergency were also described.

Effective alarm users described using a combination of fall prevention modalities to live safely at home, of which alarms were a part. Fallers across subgroups also mentioned other prevention strategies, such as home modifications, walking aids, attending group exercise sessions to improve balance, and knowing how to get up from the floor. Less effective fall prevention strategies were often described by alarm nonusers, including being more careful, or avoiding specific environmental situations which could lead to the fall.

\section{Conclusion}

Personal alarms are an effective strategy, when used appropriately, to prevent a long lie after a fall and to obtain immediate assistance. There appear to be four groups of alarm users.
Effective users of personal alarms were at the action or maintenance stage of behavior change. These people were positive about using aids and appliances to increase their independence, and were resilient in their approach to dealing with the ramifications of ageing. Another subgroup of older people felt positive about the concept of using personal alarms, but cost was the key barrier to accessing and using one. If costs were met, a personal alarm may improve these people's confidence in living alone safely, and potentially reduce harm from future falls. These people were at the contemplation stage of behavior change, and with minimal support (eg, a subsidized alarm program) could be likely to move to the action stage.

Two groups of older fallers with negative perceptions of personal alarms comprised people who had a personal alarm, but did not use it effectively or its type was inappropriate for their requirements, and fallers who were in denial regarding the risks of falling and perceived alarm use as a threat to their independence. These groups were at the precontemplation or contemplation stages of behavior change, and alternative targeted strategies would be required to influence their beliefs and behaviors.

The findings of this study provide preliminary information about the characteristics of older people who may be most likely to benefit from personal alarm devices. Future research could seek to replicate these findings in larger observational studies, and test hypotheses developed from this work in experimental studies. If confirmed, these findings could assist health care providers to target recommendations about personal alarm devices, as part of multisystem strategies to prevent harm from falls.

\section{Disclosure}

The authors report no conflicts of interest in this work.

\section{References}

1. Australian Government, Department of Health and Aging. National Strategy for and Ageing Australia. 2001. Available from: http://www. longevity-international.com/assets/National $\% 20$ Strategy $\% 20$ for $\% 20$ an\%20Ageing\%20Australia.pdf. Accessed on May 31, 2010.

2. Australian Government, Department of Health and Aging. Community Care Services. Available from: http://www.health.gov.au/internet/main/ publishing.nsf/Content/ageing-commcare-index.htm-copy3. Accessed on May 31, 2010

3. Australian Bureau of Statistics. Household and family projections 2001 to 2026, Australian Bureau of Statistics, Canberra, ACT, 2004. Available from: http://www.abs.gov.au/ausstats/abs@.nsf/productsbytopic/0AAC 8BFAE9DD3241CA2568A90013942A?OpenDocument. Accessed on May 31, 2010.

4. Deshpande N, Metter EJ, Lauretani F, Bandinelli S, Guralnik J, Ferrucci L. Activity restriction induced by fear of falling and objective and subjective measures of physical function: A prospective cohort study. J Am Geriatr Soc. 2008;56(4):615-620. 
5. Fleming J, Brayne C. Inability to get up after falling, subsequent time on floor, and summoning help: Prospective cohort study in people over 90. BMJ. 2008:337:a2227.

6. Scheffer AC, Schuurmans MJ, van Dijk N, van der Hooft T, de Rooij SE. Fear of falling: Measurement strategy, prevalence, risk factors and consequences among older persons. Age Ageing. 2008;37(1):19-24.

7. Tinetti ME, Liu WL, Claus EB. Predictors and prognosis of inability to get up after falls among elderly persons. JAMA. 1993;269(1):65-70.

8. Celler BG, Lovell NH, Chan DK. The potential impact of home telecare on clinical practice. Med J Aust. 1999;171(10):518-521.
9. Doughty $\mathrm{K}$, Lewis $\mathrm{R}$, McIntosh A. The design of a practical and reliable fall detector for community and institutional telecare. J Telemed Telecare. 2000;6 Suppl 1:S150-S154.

10. De San Miguel K, Lewin G. Personal emergency alarms: What impact do they have on older people's lives? Australas J Ageing. 2008;27(2):103-105.

11. Miskelly FG. Assistive technology in elderly care. Age Ageing. 2001;30(6):455-458.

12. Prochaska JO, Velicer WF. The transtheoretical model of health behavior change. Am J Health Promot. 1997;12(1):38-48.
International Journal of General Medicine

\section{Publish your work in this journal}

The International Journal of General Medicine is an international, peer-reviewed open-access journal that focuses on general and internal medicine, pathogenesis, epidemiology, diagnosis, monitoring and treatment protocols. The journal is characterized by the rapid reporting of reviews, original research and clinical studies across all disease areas.

\section{Dovepress}

A key focus is the elucidation of disease processes and management protocols resulting in improved outcomes for the patient.The manuscript management system is completely online and includes a very quick and fair peer-review system. Visit http://www.dovepress.com/ testimonials.php to read real quotes from published authors.

Submit your manuscript here: http://www.dovepress.com/international-journal-of-general-medicine-journal 